\title{
THE END OF FERTILITY: AGE, FECUNDITY AND FECUNDABILITY IN WOMEN
}

\author{
ODILE FRANK* $*$ P. GRACE BIANCHI $\dagger$ AND ALDO CAMPANA $\dagger$ \\ ${ }^{*}$ World Health Organization, Geneva, and $\uparrow$ Hopital Cantonal Universitaire de Genève, \\ Switzerland
}

\begin{abstract}
Summary. Onset of capacity for childbearing in women is dated biologically by menarche, although actual onset may be delayed. The end of childbearing is less understood but recent demographic and biological research on fertility at older ages is clarifying the end of fertility.

The demographic view of declining fertility with age is based on agespecific fertility in natural fertility populations, artificial insemination and pregnancy rates by age and World Fertility Survey data. New data from the Demographic and Health Surveys on exposure to the risk of pregnancy shows that whereas older women biologically need longer exposure to pregnancy, exposure declines on behavioural grounds such as duration of marriage. Actual fecundity is obscured by factors of fecundability. Recent research on medically assisted conception is adding to the understanding of declining fecundity with age, especially the relative contributions of endometrial and ovarian ageing.

This paper reviews the available information on declining fertility with age and discusses the implications of the extension of fertility through new medical technologies.
\end{abstract}

\section{Introduction}

The 1991 edition of the Guinness Book of World Records reports that the verifiably oldest woman to give birth to date was 57 years old. Clearly this woman was older than most women giving birth, yet she was younger than many men who still father children. The human species shares a great deal of common biological knowledge and predictive judgement about childbearing at older ages: at some point it is doubtful, and at some further point, impossible. These biological expectations about the age at which women give birth influence social and economic norms regarding the timing of marriage, family formation, and childbearing, as well as cultural values regarding the role of motherhood, and further expectations --both biological and social-regarding fitness of parents with age. 


\section{Methods}

The influence of age on fecundity has received little attention, aside from cataloguing observations of the decline of fecundity and fertility with age. Gray (1979) has reviewed the subject up to the late 1970s. This paper reviews the demographic and biological information on declining fecundity with age, and proposes that, at least in developed societies, the biologically well-based notions of maternal age are now challenged by new technologies that override biological constraints, but challenge current value judgements regarding pregnancy and age. Four sources of information on age and fecundity will be reviewed: data based on study of the menopause; the results of observations on artificial insemination; new behavioural information from surveys on sexual behaviour; and new findings from the practical application of assisted reproduction technology.

\section{Results}

\section{Menarche and menopause}

The onset of capacity for childbearing in women can be dated largely because of the observable biological marker of menarche, the beginning of menstrual cycles. The physiological ability to conceive, fecundity, is determined by first ovulation, which is unobservable, but sufficiently well marked by menses for practical purposes. Fecundity is probably at a low level at first, because ovulation is irregular in the earliest cycles, or not accompanied by all the necessary hormonal changes for successful pregnancy. On a social level, the realisation of early fecundity is then either desired in order for a society to maximise fertility, which may grant social and economic advantages, or not desired in societies that encourage later childbearing for demographic, economic or social reasons. Consequently, the actual onset of fecundity is limited both biologically and by behavioural constraints. Behavioural constraints on early childbearing, which are generally increasing in all human societies, influence fecundity by lowering fecundability, or the probability of a conception: norms dictate behavioural constraints that prevent individual women from realising their biological capacity to conceive.

The end of childbearing is less known, and less understood. Information that allows one to date the end of childbearing comes from three sources: data on women's menopausal status relative to age, principally from medical research (menopause, the end of menstruation, is more truly characterised by the cessation of ovarian follicular function, which is detectable but not 'visible': WHO Scientific Group, 1981); data on the age of women at the birth of their children in societies that do not practise family limitation (i.e. have a pattern of natural fertility), principally from demographic research on fertility in historical populations; and, most recently, data on achieved pregnancy rates following artificial insemination of women of different ages presumed fecund.

Gray (1979), reporting on menopause with age in various populations, developed and developing, shows that the proportion of women who cease menstruating begins to increase in the late $30 \mathrm{~s}$, then increases to about $20 \%$ in the mid-40s and to virtually $100 \%$ in the mid-50s. These observations inform us less on the end of childbearing than menarche does about its onset. One reason for this is that as a marker for the 
Table 1. Estimates of the mean age at last birth of women in historical populations

\begin{tabular}{|c|c|c|}
\hline & & Age (years) \\
\hline \multicolumn{3}{|l|}{ German villages (pre-1850) } \\
\hline Grafenhausen & & $39 \cdot 7$ \\
\hline Oshselbronn & & $39 \cdot 2$ \\
\hline Three Bavarian villages & & $40 \cdot 6$ \\
\hline Four Waldeck villages & & $40 \cdot 7$ \\
\hline Werdum & & $39 \cdot 4$ \\
\hline \multicolumn{3}{|l|}{ All villages } \\
\hline \multirow[t]{2}{*}{ Age at marriage: } & 25 & $40 \cdot 3$ \\
\hline & $25-29$ & $40 \cdot 1$ \\
\hline \multirow[t]{3}{*}{ Occupation of husband: } & artisans & $39 \cdot 8$ \\
\hline & farmers & $39 \cdot 8$ \\
\hline & landless & $40 \cdot 1$ \\
\hline \multicolumn{3}{|l|}{ No. of infant deaths } \\
\hline \multirow[t]{3}{*}{ of first two children } & 0 & $40 \cdot 1$ \\
\hline & 1 & $40 \cdot 4$ \\
\hline & 2 & $40 \cdot 4$ \\
\hline \multicolumn{3}{|l|}{ North American communities } \\
\hline \multicolumn{2}{|l|}{ Canada (17th century) } & $40 \cdot 1$ \\
\hline \multicolumn{2}{|l|}{ Canada ( 18 th century) } & $41 \cdot 0$ \\
\hline \multicolumn{2}{|l|}{ Bois-Vert } & $40 \cdot 7$ \\
\hline \multicolumn{2}{|l|}{ St Jean-de-Cherbourg } & $38 \cdot 6$ \\
\hline \multicolumn{2}{|l|}{ Hingham } & $39 \cdot 1$ \\
\hline \multicolumn{2}{|l|}{ Quakers } & $39 \cdot 6$ \\
\hline \multicolumn{2}{|l|}{ Hutterites } & $40 \cdot 9$ \\
\hline \multicolumn{2}{|l|}{ Bris } & $38 \cdot 7$ \\
\hline \multicolumn{3}{|l|}{ French parishes } \\
\hline \multicolumn{2}{|l|}{ Crulai } & $40 \cdot 0$ \\
\hline \multicolumn{2}{|l|}{ Tourouvre au Perche } & $40 \cdot 3$ \\
\hline \multicolumn{3}{|l|}{ English population } \\
\hline (mid-19th century) & & $41 \cdot 7$ \\
\hline
\end{tabular}

Source: Bongaarts \& Potter (1983).

end of menstrual cycles, and presumed ovulation, the menopause is not a well-defined event, being confirmed only retrospectively, usually after 12 months of amenorrhoea. In addition, menopause is not an accurate indicator of the end of fecundity. The demographic data on age of women at last birth (Table 1) demonstrate that, whereas the median age of onset of menopause is around 48-50 years (extrapolated from data on perimenopausal and postmenopausal women), the average age at last birth in several populations known not to control fertility ranges narrowly around 39-41 years (mean 40 years).

By observation, therefore, fecundity generally ceases some considerable time before menopause. On the basis of Henry's (1965) and Vincent's (1950) estimates of 
proportions of infecund couples by age from data on historical populations that did not practise birth limitation, Bongaarts \& Potter (1983) calculated the average age at onset of infecundity at about 41.7 years. This estimate can be related to an average age at last birth of about 40 years, because some women who are fecund will nevertheless not give birth, whereas no infecund woman will give birth. Similarly, on the basis of a model of the increase in proportions of women infecund by age, Gray (1979) estimates the difference between median age of infecundity and median age of menopause to be around 8 years, and the difference between the median age at last birth and median age of menopause to be about 10 years.

\section{Artificial insemination findings}

These estimates confirm that, in most women, fecundity ceases when observable and detectable biological events (menstrual cycles and ovulation) may still be occurring regularly. The cessation of fecundity is an invisible biological event whose onset is undetectable, except through its consequences for fertility. In the early 1980 s, research on infecund couples seeking treatment in whom the men were found sterile, or infecund and the women were presumed fecund, and who were offered artificial insemination with donor sperm, apparently revealed that the onset of infecundity with age had been underestimated. Indeed, the CECOS study of 1982 suggested that there was already a significant decline in conception rates in women in their 30s: whereas about a quarter of women aged under 26 and 26-30 years did not conceive in twelve cycles of insemination, over $40 \%$ of women aged $31-35$ and over half of the women aged 36 and over failed to do so (Schwartz \& Mayaux, 1982).

Bongaarts (1982) pointed out that there was good demographic evidence to show that natural insemination results in higher conception rates at all ages, and that sterility was overestimated if only twelve cycles were observed, as a substantial proportion of women at all ages conceive after more than 12 months of 'exposure' to the chance of pregnancy. Bongaarts concluded that in other circumstances, higher pregnancy rates would be achieved at all ages, and that the decline of fecundity with age would probably be less steep, i.e. that more biases were operating against the older, as compared with the younger women in the CECOS study.

Another factor to take into consideration is the declining quality of oocytes in older women. Thus, if older women have fewer 'good' cycles they will be disadvantaged in comparison with younger women during a fixed number of cycles of insemination. On the basis of 555 pregnancies following artificial insemination in 751 women aged 18-42, van Noord-Zaadastra et al. (1991) calculated that the pregnancy rate in women 31 years and over was only two-thirds of that for women 20-31 years after twelve cycles of insemination (0.54:0.74), whereas it had reached almost $90 \%$ of the younger women's rate after 24 cycles $(0 \cdot 75: 0 \cdot 85)$.

When assessing studies using artificial insemination data it must also be borne in mind that in infecund couples with a 'male factor', the older the woman the more likely it is that she is selected for higher infecundity: she has had more time to have a spontaneous pregnancy, even with poor quality sperm. Some younger women, if they did not seek artificial insemination might still have a spontaneous pregnancy.

The reasons that natural insemination would result in higher conception rates at all ages are probably two-fold. (1) Conception rates from artificial insemination were 
achieved with frozen, not fresh sperm, whereas sterility research has shown that fresh sperm results in higher pregnancy rates than frozen sperm at all ages, a fact not discussed by Bongaarts. (2) Natural insemination can entail more acts of insemination around the time of ovulation, increasing the probability of conception. Barrett \& Marshall (1969) calculated that two to four coital acts in the 6-day period around ovulation resulted in a conception rate twice that for one act in the same period $(0.34 \cdot 0 \cdot 41: 0 \cdot 17)$ (see Bongaarts \& Potter, 1983). Another study found that daily coital acts for the week around the time of ovulation could result in a probability of conception of 0.49 (cited in Bongaarts, 1982). These reasons illustrate, and Bongaarts' study demonstrates, the need to consider both biological and behavioural factors in assessing fecundity and its decline with age. Accordingly, whereas the quality of sperm is a biological factor that will affect the relative success of artificial and natural insemination, frequency of intercourse is a behavioural influence that not only helps to explain the low fecundity of women who are artificially inseminated but probably contributes to all demographic inferences regarding the decline of fecundity with age relying, as they do, principally on the outward manifestation of fertility (or infertility).

\section{Survey data on sexual behaviour}

The Demographic and Health Surveys included, for the first time in a series of fertility surveys, questions on sexual relations. A basic question asks if the respondent has ever had sexual intercourse. Another question asks about age at first sexual intercourse. Then three questions ask (1) if the respondent has had sexual intercourse in the last 4 weeks, (2) if so, how many times, and (3) when was the last time she had sexual intercourse (Institute for Resource Development, 1987a,b).

The quality of data collected with the three last questions in the 23 countries discussed here appears to be fairly good (Blanc \& Rutenberg, 1991). (Fourteen countries used all the questions, four used only the first two, and five used only the last one). One problem is heaping of reported coital frequencies, at 4, 8 and 12 times in the last 4 weeks. As Blanc \& Rutenberg point out, there is a possibility that settled couples do in fact have sexual relations at particular times that gives their coital frequency a certain regularity. Also, respondents may make an estimate based on one week's average experience multiplied by four, so that reported frequency will necessarily heap on multiples of 4 (Westoff, 1974). The question on coital frequency thus elicits different responses from those to the question on time since last intercourse, and some inconsistencies emerge: women may reply more normatively to the first question, but more experientially to the second.

For the present study, it is the change in reported coital frequency, including time since last intercourse, with age which is of interest. Assuming that the absolute levels of reported coital frequency may be inexact, but that at all ages they are subjected to the same biases, the frequency of coitus with age should provide information on the possible contribution of behaviour to the translation of fecundity into fertility. Indeed, one reason that fecundity is not fully realised in natural fertility populations, both historical and contemporary, may be that the probability of conception, or fecundability, is reduced because women are less exposed to the risk of pregnancy, i.e. 
Table 2. Mean monthly coital frequency of all women by age, Demographic and Health Surveys, 18 countries, late 1980s

\begin{tabular}{|c|c|c|c|c|c|c|c|}
\hline \multirow[b]{2}{*}{ Country } & \multicolumn{7}{|c|}{ Age group (years) } \\
\hline & $15-19$ & $20-24$ & $25-29$ & $30-34$ & $35-39$ & $40-44$ & $45-49$ \\
\hline \multicolumn{8}{|l|}{ Africa } \\
\hline Burundi & 7 & 6 & 6 & 6 & 5 & 4 & 5 \\
\hline Ghana & 1 & 1 & 1 & 1 & 1 & 1 & 1 \\
\hline Kenya & 1 & 2 & 3 & 3 & 3 & 2 & 2 \\
\hline Mali & 1 & 1 & 1 & 1 & 1 & 1 & 0 \\
\hline Nigeria (Ondo) & 1 & 1 & 1 & 1 & 1 & 1 & 1 \\
\hline Uganda & 4 & 5 & 5 & 5 & 4 & 4 & 3 \\
\hline Sudan & 6 & 5 & 4 & 4 & 4 & 4 & 3 \\
\hline \multicolumn{8}{|l|}{ Latin America } \\
\hline Bolivia & 1 & 2 & 2 & 2 & 2 & 2 & 1 \\
\hline Brazil & 7 & 7 & 8 & 7 & 6 & 6 & 一 \\
\hline Colombia & 3 & 4 & 5 & 4 & 4 & 3 & 3 \\
\hline Dominican Republic & 3 & 3 & 3 & 3 & 2 & 2 & 2 \\
\hline Ecuador & 4 & 4 & 4 & 4 & 4 & 3 & 3 \\
\hline Guatemala & 4 & 4 & 4 & 4 & 4 & 3 & - \\
\hline Mexico & 1 & 2 & 3 & 3 & 2 & 2 & 1 \\
\hline Peru & 3 & 4 & 4 & 4 & 3 & 3 & 2 \\
\hline \multicolumn{8}{|l|}{ Asia } \\
\hline Indonesia & 5 & 4 & 4 & 3 & 3 & 2 & 1 \\
\hline Sri Lanka & 6 & 5 & 5 & 5 & 4 & 3 & 2 \\
\hline Thailand & 5 & 4 & 4 & 3 & 3 & 2 & 2 \\
\hline $\begin{array}{l}\text { Unweighted } \\
\text { simple mean }\end{array}$ & $3 \cdot 5$ & $3 \cdot 6$ & $3 \cdot 7$ & $3 \cdot 5$ & $3 \cdot 1$ & $2 \cdot 7$ & 2 \\
\hline
\end{tabular}

their coital frequency is lower. One phenomenon that may be especially sensitive to underestimates of fecundability is the decline of fecundity with age.

Table 2 displays the mean 'monthly' coital frequency of all women, by age, for the eighteen countries which collected data on sexual relations in the last 4 weeks in their Demographic and Health Survey in the late 1980s, for individual countries grouped by region. The ordinary arithmetic mean illustrates the average frequency reported for a country (rather than the true mean for all the populations of women involved). The average frequency by age for the eighteen countries combined is shown in Fig. 1.

The trend in coital frequency is fairly clear, and, to a degree, intuitive, for either individual country data, or the simple summary statements. Coital frequency is more or less stable from 15 years to the mid-30s, and then declines systematically and substantially to age 49 . As the data include all women, not just currently or ever-married women, coital frequency is a little lower in the youngest age groups and peaks at 25-29 years, but these differences are probably not significant.

These data confirm that, at least for these 18 countries, there is a non-negligible decline in coital frequency with age and they have new implications for estimates of 


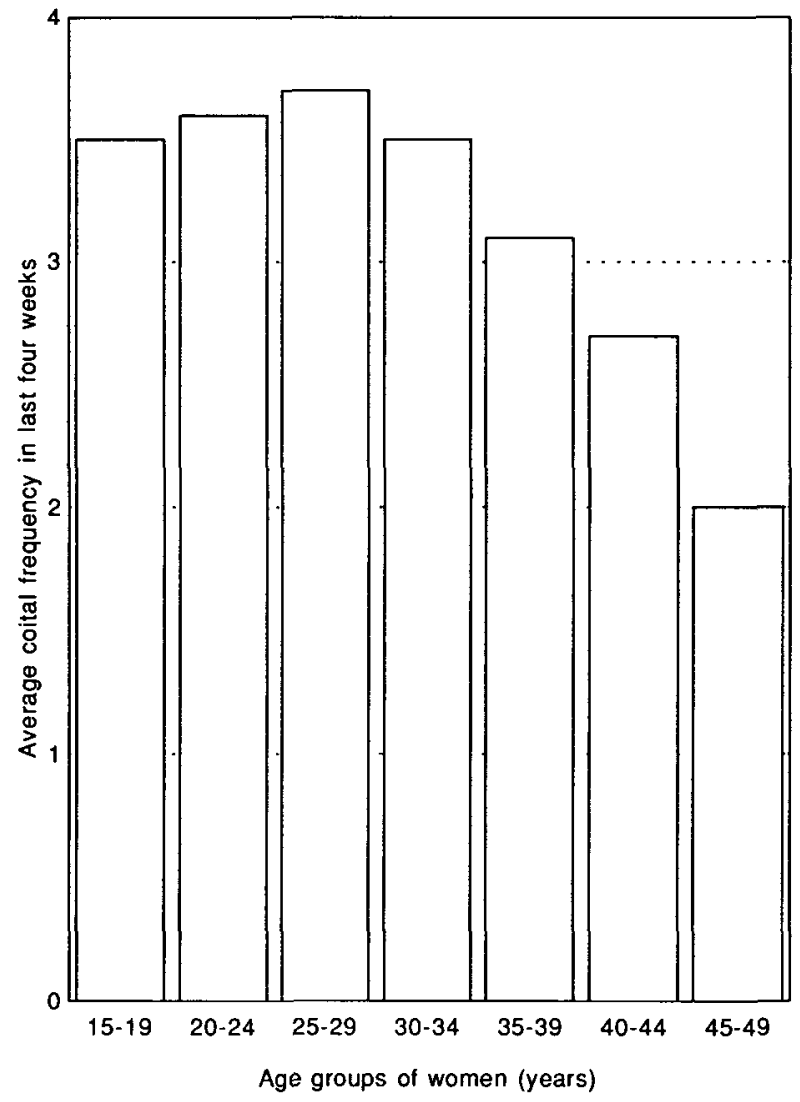

Fig. 1. Coital frequency (no. of acts) by age, last 4 weeks. Average for 18 countries.

the fertility-inhibiting effect of contraceptive prevalence (Blanc \& Rutenberg, 1991). Notably, the contribution of contraceptive prevalence to low fertility is probably overestimated in older women. Similarly, however, the data suggest that the decline of fecundity with age is overestimated, if women's apparent reduced fecundability after the mid-30s is not taken into account. Such a finding was not unexpected, however, and had been anticipated and confirmed in earlier models that had attempted to estimate the extent of the effect (Menken, Trussell \& Larsen, 1986).

One reason for the decline of coital frequency with age is that in general, older women have been married for longer, and marriage duration, which is closely related to women's age, influences level of sexual interest (James, 1983). In Table 3 and Fig. 2 which illustrate mean monthly coital frequency by duration of marriage in the countries, the trend is the same, but more clearly expressed. By 30 or more years of marriage, women report half the coital frequency of women married for less than 4 years.

The role of low exposure to the risk of pregnancy in declining fecundity is shown by the data on time since last sexual relations. Tables 4, 5, 6 and 7 show the 
Table 3. Mean monthly coital frequency by duration of marriage, Demographic and Health Surveys, 18 countries, late 1980s

\begin{tabular}{|c|c|c|c|c|c|c|c|}
\hline \multirow[b]{2}{*}{ Country } & \multicolumn{7}{|c|}{ Duration of marriage (years) } \\
\hline & $0-4$ & $5-9$ & $10-14$ & $15-19$ & $20-24$ & $25-29$ & $30+$ \\
\hline \multicolumn{8}{|l|}{ Africa } \\
\hline Burundi & 7 & 6 & 6 & 6 & 4 & 4 & 5 \\
\hline Ghana & 1 & 1 & 1 & 1 & 1 & 1 & 1 \\
\hline Kenya & 3 & 3 & 3 & 3 & 2 & 2 & 2 \\
\hline Mali & 1 & 1 & 1 & 1 & 1 & 1 & 0 \\
\hline Nigeria (Ondo) & 1 & 1 & 1 & 1 & 1 & 1 & 1 \\
\hline Uganda & 6 & 6 & 5 & 4 & 4 & 4 & 3 \\
\hline Sudan & 4 & 4 & 4 & 4 & 4 & 4 & 3 \\
\hline \multicolumn{8}{|l|}{ Latin America } \\
\hline Bolivia & 2 & 2 & 2 & 2 & 2 & 1 & 1 \\
\hline Brazil & 8 & 8 & 8 & 6 & 6 & 6 & 3 \\
\hline Colombia & 5 & 5 & 5 & 4 & 3 & 3 & 3 \\
\hline Dominican Republic & 4 & 3 & 3 & 3 & 2 & 2 & 1 \\
\hline Ecuador & 4 & 4 & 4 & 4 & 4 & 3 & 2 \\
\hline Guatemala & 4 & 4 & 4 & 4 & 3 & 3 & 0 \\
\hline Mexico & 3 & 3 & 3 & 3 & 2 & 2 & 1 \\
\hline Peru & 4 & 4 & 4 & 3 & 3 & 2 & 2 \\
\hline \multicolumn{8}{|l|}{ Asia } \\
\hline Indonesia & 5 & 4 & 4 & 3 & 3 & 2 & 1 \\
\hline Sri Lanka & 5 & 4 & 5 & 4 & 3 & 2 & 2 \\
\hline Thailand & 4 & 4 & 3 & 3 & 2 & 2 & 1 \\
\hline $\begin{array}{l}\text { Unweighted } \\
\text { simple mean }\end{array}$ & 3.9 & $3 \cdot 7$ & 3.7 & $3 \cdot 3$ & $2 \cdot 8$ & $2 \cdot 5$ & 2 \\
\hline
\end{tabular}

proportions of women who report not having had sexual relations in the last four weeks, 3, 6, and 12 months for the nineteen countries which collected this information. Again, arithmetic means were calculated for the sake of simplicity.

The results show that the proportions of women who report not having had sexual relations increase with age, and decrease with time elapsed. For the older women, 35-39 and 45-49 years respectively, and given that several months of exposure are necessary for pregnancy (Bongaarts \& Potter, 1982) the average proportions of $12 \%$ and $19 \%$ who have not had sexual relations in 6 months, or $9 \%$ and $14 \%$ in a year are noteworthy, particularly in view of the variation between countries, which allows for some far higher proportions not only in natural fertility societies such as Ghana, Mali, Nigeria, Togo in Africa, and Bolivia in Latin America, but also in three Asian countries where fertility is substantially regulated.

On the basis of the findings for coital frequency by age and marriage duration, one can infer that duration of marriage would show a similar picture regarding time elapsed since last sexual intercourse. As women's age and marriage duration are closely associated (James, 1983), and as women's age, rather than marriage duration, 


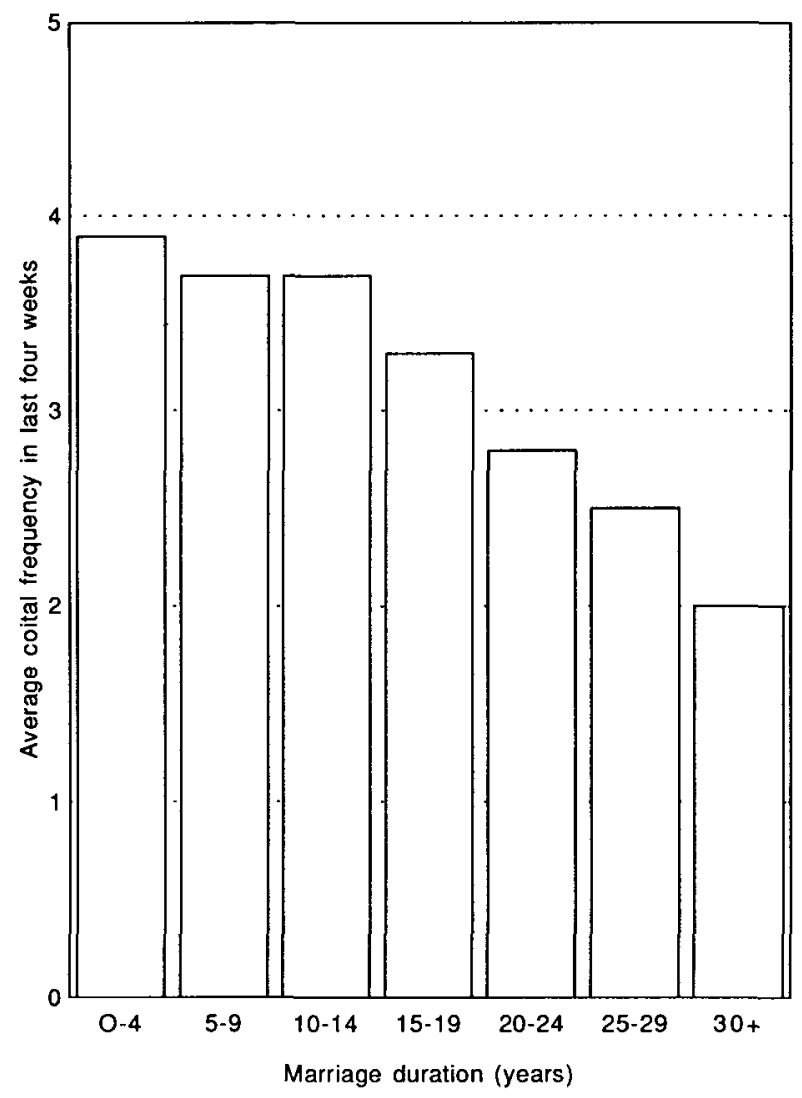

Fig. 2. Coital frequency (no. of acts) by marriage duration, last 4 weeks. Average for 18 countries.

is utilised not only in fertility measurement but in evaluation of fecundity levels, women's age seems a sufficient dimension to illustrate here.

Figure 3 illustrates the summary data in Tables 4 to 7 . Again, the trends over time and by age are straightforward. Even if the absolute levels of reported sexual activity are inflated, or deflated, overall (there is little information on the validity of these data on sexual frequency: Blanc \& Rutenberg, 1991) the relative orders of magnitude of the levels reported over time, assuming that women of all ages are subjected to the same reporting biases, are remarkable (for issues of validity of coital frequency reporting in the USA, see Hornsby \& Wilcox, 1989).

Other factors than the simple decline of coital frequency with duration of marriage may also operate to produce trends such as shown in Fig. 4. Variability in the exposure of women to the risk of pregnancy at older ages probably depends in large part on cultural forces, both direct and indirect. In a few societies it is not acceptable for a woman to become a mother after she has become a grandmother, so the earlier the age at marriage, the younger the age at which women will cease sexual relations. Marriage stability, and the chances of divorce and remarriage will also influence the 
Table 4. Percentage of currently married women who have not had sexual relations in the last 4 weeks by age, Demographic and Health Surveys, 19 countries, late 1980s

\begin{tabular}{|c|c|c|c|c|c|c|c|}
\hline \multirow[b]{2}{*}{ Country } & \multicolumn{7}{|c|}{ Age group (years) } \\
\hline & $15-19$ & $20-24$ & $25-29$ & $30-34$ & $35-39$ & $40-44$ & $45-49$ \\
\hline \multicolumn{8}{|l|}{ Africa } \\
\hline Botswana & 35 & 34 & 34 & 30 & 25 & 35 & 27 \\
\hline Burundi & 9 & 24 & 22 & 26 & 25 & 32 & 29 \\
\hline Ghana & 59 & 58 & 55 & 51 & 52 & 52 & \\
\hline Kenya & 33 & 30 & 29 & 30 & 32 & 35 & 53 \\
\hline Liberia & 38 & 41 & 40 & 42 & 37 & 42 & 29 \\
\hline Mali & 47 & 39 & 40 & 33 & 41 & 33 & 50 \\
\hline Nigeria (Ondo) & 59 & 64 & 68 & 65 & 71 & 71 & 84 \\
\hline Uganda & 19 & 18 & 18 & 24 & 21 & 26 & 37 \\
\hline Sudan & 28 & 37 & 35 & 36 & 32 & 35 & 43 \\
\hline Togo & 52 & 58 & 56 & 63 & 62 & 65 & 64 \\
\hline Zimbabwe & 26 & 26 & 19 & 19 & 18 & 21 & 22 \\
\hline \multicolumn{8}{|l|}{ Latin America } \\
\hline Bolivia & 45 & 42 & 38 & 36 & 42 & 42 & 54 \\
\hline Brazil & 11 & 11 & 8 & 9 & 12 & 13 & - \\
\hline Colombia & 28 & 21 & 15 & 19 & 18 & 26 & 27 \\
\hline Guatemala & 28 & 31 & 32 & 27 & 28 & 29 & - \\
\hline Trinidad & 10 & 10 & 7 & 7 & 9 & 13 & 22 \\
\hline \multicolumn{8}{|l|}{ Asia } \\
\hline Indonesia & 18 & 18 & 17 & 17 & 22 & 28 & 44 \\
\hline Sri Lanka & 20 & 22 & 20 & 18 & 19 & 29 & 42 \\
\hline Thailand & 16 & 16 & 16 & 18 & 22 & 32 & 43 \\
\hline $\begin{array}{l}\text { Unweighted } \\
\text { simple mean }\end{array}$ & $30 \cdot 6$ & $31 \cdot 6$ & 30 & $30 \cdot 3$ & $30 \cdot 9$ & $34 \cdot 7$ & $42 \cdot 5$ \\
\hline
\end{tabular}

exposure of women at older ages, by modifying their duration of marriage, and the level of sexual interest of the couple. As the acceptability of extramarital relations is culturally variable, the degree to which women are reporting sexual behaviour that applies to sexual partners other than their spouse or regular partner remains unknown (as does the prevalence of extramarital relations by age, and by marriage duration).

Some age-related factors may bias the estimates of coital frequency of young women downward, thereby causing an underestimate of the decline in exposure with age, and further undermining the assumption of equal exposure at all ages. Societies vary in their proscriptions regarding sex during pregnancy. As younger women will have more periods of proscription during pregnancy (as well as of abstinence during the postpartum period) than older women, and the more so the higher the level of fertility, the tendency would be for coital frequency to be an underestimate in young age groups of women, particularly in high fertility societies. Against this, if the increase in sexual interest of women with age that has been studied in some developed 
Table 5. Percentage of currently married women who have not had sexual relations in the last 3 months by age, Demographic and Health Surveys, 19 countries, late 1980s

\begin{tabular}{|c|c|c|c|c|c|c|c|}
\hline \multirow[b]{2}{*}{ Country } & \multicolumn{7}{|c|}{ Age group (years) } \\
\hline & $15-19$ & $20-24$ & $25-29$ & $30-34$ & $35-39$ & $40-44$ & $45-49$ \\
\hline \multicolumn{8}{|l|}{ Africa } \\
\hline Botswana & 24 & 21 & 19 & 18 & 11 & 13 & 11 \\
\hline Burundi & 4 & 7 & 6 & 8 & 9 & 10 & 11 \\
\hline Ghana & 41 & 39 & 33 & 37 & 33 & 32 & 35 \\
\hline Kenya & 18 & 16 & 15 & 16 & 14 & 19 & 23 \\
\hline Liberia & 25 & 30 & 29 & 29 & 25 & 19 & 15 \\
\hline Mali & 28 & 19 & 22 & 20 & 22 & 19 & 31 \\
\hline Nigeria (Ondo) & 44 & 50 & 54 & 52 & 53 & 55 & 74 \\
\hline Uganda & 8 & 7 & 8 & 11 & 8 & 14 & 20 \\
\hline Sudan & 12 & 17 & 18 & 18 & 17 & 16 & 23 \\
\hline Togo & 36 & 45 & 41 & 42 & 45 & 46 & 50 \\
\hline Zimbabwe & 14 & 11 & 8 & 9 & 8 & 10 & 11 \\
\hline \multicolumn{8}{|l|}{ Latin America } \\
\hline Bolivia & 24 & 23 & 21 & 15 & 21 & 23 & 35 \\
\hline Brazil & 4 & 4 & 3 & 4 & 4 & 6 & - \\
\hline Colombia & 3 & 5 & 3 & 6 & 5 & 8 & 11 \\
\hline Guatemala & 15 & 14 & 17 & 14 & 14 & 15 & - \\
\hline Trinidad & 2 & 5 & 2 & 3 & 4 & 5 & 8 \\
\hline \multicolumn{8}{|l|}{ Asia } \\
\hline Indonesia & 9 & 9 & 8 & 7 & 11 & 15 & 30 \\
\hline Sri Lanka & 11 & 12 & 12 & 9 & 10 & 16 & 31 \\
\hline Thailand & 5 & 7 & 6 & 7 & 8 & 11 & 23 \\
\hline $\begin{array}{l}\text { Unweighted } \\
\text { simple mean }\end{array}$ & $17 \cdot 2$ & 18 & $17 \cdot 1$ & $17 \cdot 1$ & $17 \cdot 0$ & $18 \cdot 3$ & 26 \\
\hline
\end{tabular}

societies is culture-dependent rather than universal, declines in coital frequency with age may be underestimated in some societies relative to others.

\section{Findings from assisted reproductive technology}

Although the decrease in fecundity with age is undoubtedly influenced by decreasing sexual activity with age, it remains that biological factors determine the underlying decline over the lifespan in female capacity to conceive and carry to term a pregnancy. Reasons for the biological phenomenon have not been well defined, particularly in regard to the contribution of various potential biological parameters implicated in the decline.

The availability of new assisted reproductive technology (ART) procedures has recently created a new important study model, at the same time that it has provided possible solutions for infecund couples. These technologies have been developed and become more accessible at the same time that post-war generations who delayed 
Table 6. Percentage of currently married women who have not had sexual relations in the last 6 months by age, Demographic and Health Surveys, 19 countries, late 1980s

\begin{tabular}{|c|c|c|c|c|c|c|c|}
\hline \multirow[b]{2}{*}{ Country } & \multicolumn{7}{|c|}{ Age group (years) } \\
\hline & $15-19$ & $20-24$ & $25-29$ & $30-34$ & $35-39$ & $40-44$ & $45-49$ \\
\hline \multicolumn{8}{|l|}{ Africa } \\
\hline Botswana & 9 & 10 & 10 & 9 & 6 & 7 & 7 \\
\hline Burundi & 1 & 4 & 2 & 4 & 4 & 7 & 7 \\
\hline Ghana & 26 & 27 & 22 & 22 & 23 & 21 & 24 \\
\hline Kenya & 7 & 8 & 8 & 9 & 7 & 12 & 15 \\
\hline Liberia & 5 & 18 & 19 & 20 & 18 & 10 & 10 \\
\hline Mali & 16 & 9 & 11 & 11 & 10 & 9 & 21 \\
\hline Nigeria (Ondo) & 29 & 34 & 41 & 40 & 42 & 42 & 60 \\
\hline Uganda & 4 & 3 & 4 & 5 & 4 & 6 & 15 \\
\hline Sudan & 8 & 10 & 10 & 11 & 10 & 9 & 16 \\
\hline Togo & 26 & 34 & 30 & 31 & 35 & 37 & 36 \\
\hline Zimbabwe & 3 & 5 & 3 & 5 & 4 & 4 & 8 \\
\hline \multicolumn{8}{|l|}{ Latin America } \\
\hline Bolivia & 14 & 15 & 12 & 9 & 13 & 18 & 30 \\
\hline Brazil & 4 & 2 & 2 & 2 & 3 & 4 & - \\
\hline Colombia & 0 & 1 & 1 & 4 & 3 & 6 & 9 \\
\hline Guatemala & 13 & 9 & 12 & 11 & 8 & 11 & - \\
\hline Trinidad & 0 & 1 & 1 & 1 & 2 & 3 & 5 \\
\hline \multicolumn{8}{|l|}{ Asia } \\
\hline Indonesia & 3 & 4 & 4 & 4 & 6 & 9 & 20 \\
\hline Sri Lanka & 3 & 5 & 6 & 5 & 6 & 12 & 26 \\
\hline Thailand & 2 & 3 & 3 & 4 & 4 & 5 & 14 \\
\hline $\begin{array}{l}\text { Unweighted } \\
\text { simple mean }\end{array}$ & $9 \cdot 1$ & 10.6 & $10 \cdot 6$ & $10 \cdot 9$ & 11 & $12 \cdot 2$ & 19 \\
\hline
\end{tabular}

childbearing have created a demand for help to solve the problems of starting childbearing at older ages.

The technique of in-vitro fertilisation (IVF) consists of removing oocytes from maturing follicles, fertilising them with prepared sperm in a test-tube and then transferring the early embryos into the uterus. The technique was first developed to treat women whose fallopian tubes (and hence passage of the fertilised embryo to the uterus) were impaired. Data from IVF series confirm that success rates begin to decline around the age of 35-37 years (Padilla \& Garcia, 1989; Segal \& Casper, 1990; Piette et al., 1990). This decline in fecundity does not appear to be explained by differential distribution of sterility diagnoses, the number of IVF attempts (Medical Research International et al., 1992), husband's age, or type of ovarian stimulation (Piette et al., 1990).

Data from assisted reproductive technology in relation to the timing of fecundity decline could be subject to the same potential biases and errors as when data on artificial insemination are used. The useful application of the IVF data is not in dating 
Table 7. Percentage of currently married women who have not had sexual relations in the last 12 months by age, Demographic and Health Surveys, 19 countries, late 1980s

\begin{tabular}{|c|c|c|c|c|c|c|c|}
\hline \multirow[b]{2}{*}{ Country } & \multicolumn{7}{|c|}{ Age group (years) } \\
\hline & $15-19$ & $20-24$ & $25-29$ & $30-34$ & $35-39$ & $40-44$ & $45-49$ \\
\hline \multicolumn{8}{|l|}{ Africa } \\
\hline Botswana & 1 & 2 & 3 & 5 & 2 & 5 & 5 \\
\hline Burundi & 0 & 2 & 1 & 2 & 2 & 5 & 6 \\
\hline Ghana & 12 & 16 & 13 & 13 & 14 & 14 & 19 \\
\hline Kenya & 3 & 4 & 5 & 4 & 6 & 9 & 13 \\
\hline Liberia & 4 & 8 & 7 & 7 & 7 & 3 & 7 \\
\hline Mali & 8 & 5 & 6 & 6 & 5 & 7 & 17 \\
\hline Nigeria (Ondo) & 16 & 17 & 24 & 24 & 30 & 31 & 47 \\
\hline Uganda & 0 & 1 & 1 & 1 & 2 & 4 & 10 \\
\hline Sudan & 4 & 5 & 7 & 7 & 7 & 7 & 13 \\
\hline Togo & 12 & 9 & 6 & 10 & 24 & 28 & 26 \\
\hline Zimbabwe & 1 & 2 & 1 & 2 & 2 & 3 & 5 \\
\hline \multicolumn{8}{|l|}{ Latin America } \\
\hline Bolivia & 6 & 10 & 8 & 6 & 10 & 15 & 29 \\
\hline Brazil & 3 & 2 & 1 & 2 & 3 & 4 & - \\
\hline Colombia & 0 & 0 & 1 & 2 & 1 & 6 & 8 \\
\hline Guatemala & 12 & 7 & 9 & 9 & 7 & 7 & - \\
\hline Trinidad & 0 & 1 & 0 & 1 & 1 & 2 & 5 \\
\hline \multicolumn{8}{|l|}{ Asia } \\
\hline Indonesia & 2 & 2 & 2 & 2 & 4 & 6 & 16 \\
\hline Sri Lanka & 1 & 2 & 3 & 3 & 4 & 11 & 22 \\
\hline Thailand & 1 & 1 & 2 & 3 & 2 & 4 & 13 \\
\hline $\begin{array}{l}\text { Unweighted } \\
\text { simple mean }\end{array}$ & $4 \cdot 5$ & $5 \cdot 1$ & $5 \cdot 3$ & $5 \cdot 7$ & 7 & 9 & $13 \cdot 7$ \\
\hline
\end{tabular}

the decline so much as in elucidating the sources of declining fecundity with age. This issue is important, as the time limits of fecundity depend on the nature, and consequently the alterability, of the underlying phenomena.

Accordingly, attention has been focused on investigating the relative roles of a decrease in oocyte production, a decrease in viability of the embryo due to oocyte quality (related to a rise in the rate of spontaneous abortions), and of alteration of the implantation process due to uterine dysfunction at older age. Results supporting the major alternatives, whether declining IVF success with age is principally due to the ageing ovary, or to the ageing uterus, have been reported.

Kerin et al. (1984) showed that there was a decrease in the number of oocytes produced, as well as in the fertilisation rates for older women and many studies have since confirmed these observations. Other IVF groups reported a reduction in implantation rates that could be explained by a reduction in the 'quality' of the uterus, and of its lining, the endometrium. Possible reasons for the declining uterine receptivity include: fibromatosis, and reduced density of endometrial villi, which 


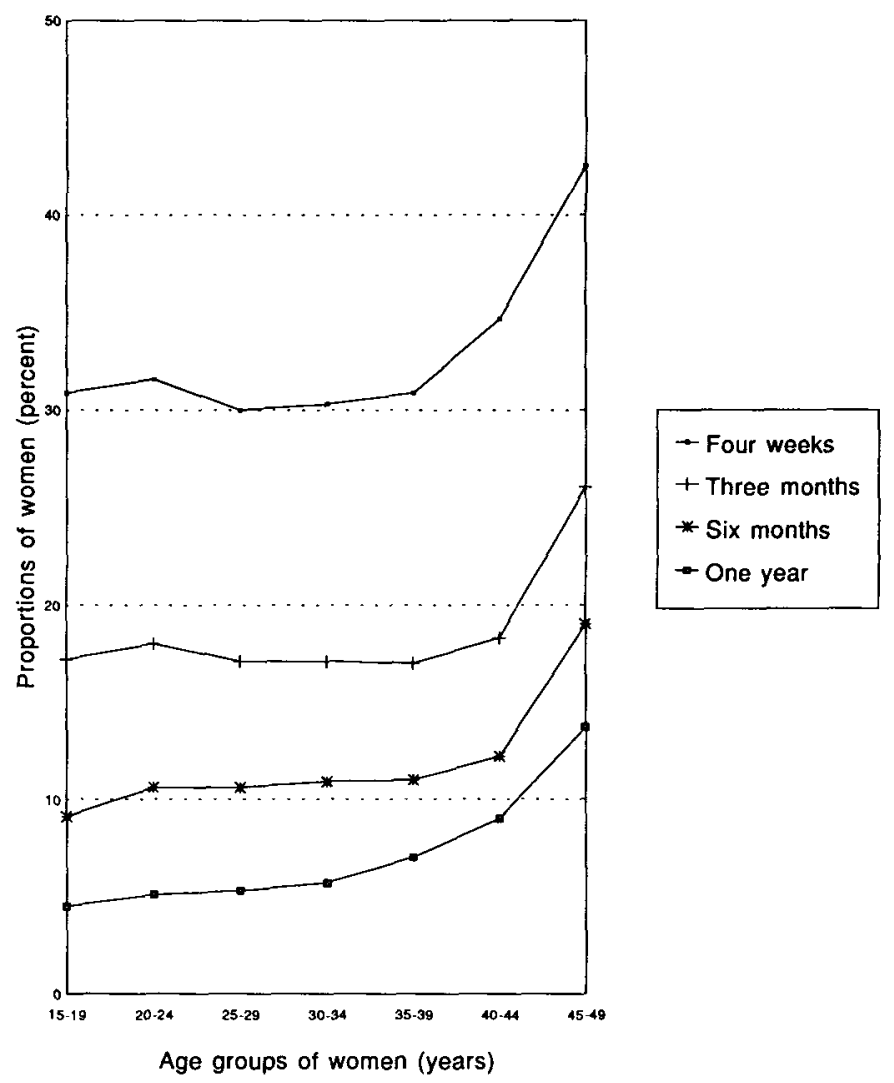

Fig. 3. Time elapsed since last sexual relations: percentage of women by age who have had no sexual relations in the elapsed interval. Average for 19 countries.

would make less of the surface of the endometrium hospitable to the embryo; reduced blood flow to the endometrial surface; alteration of the capacity to synthesise necessary hormones, such as prostaglandins, with age; deficiency of the corpus luteum on the ovary (which develops from the follicle that contained the oocyte) to produce hormones required to maintain pregnancy (progesterone, oestrogen) (Gosden, 1985); and, a reduction in the number of oestrogen and progesterone receptors with age (which reduces the ability of the uterus to respond to the hormones of pregnancy), a hypothesis supported only in data on animals (Saidduddin \& Zussenhaus, 1979).

Many of these hypotheses have been re-examined in the light of recent research that permits separate determination of the role of the ovary and the role of the uterus in the IVF process and success rates. Oocytes or embryos donated by younger fecund women undergoing IVF are transferred to women of known ages who have no ovarian function (due to absence of ovaries, or postmenopausal ovaries) after a regimen of hormonal substitution that simulates natural menstrual cycling: consequent pregnancies are also given external hormonal support (to replace the corpus luteum) until the placenta takes over all hormone production needed to sustain pregnancy. 
Following the establishment of the first oocyte donation programmes, and a few reports of successful oocyte donation (Lutjen et al., 1984; Sauer, Paulson \& Lobo, 1989; Jacobson \& Galen, 1990), Sauer, Paulson \& Lobo (1990) reported on the success of oocyte donation to seven women $40-44$ years with ovarian failure. Whereas the chances of success of this group in IVF following ovarian stimulation can be estimated at below $10 \%$ per cycle, following the protocol of oocyte donation, the women achieved a successful pregnancy rate of $55 \%$ per cycle (five live births for nine cycles of donation), which was comparable to the success rate of younger women receiving donated embryos. This result offered strong support to the hypothesis that it is the ovary, rather than the endometrium, that most contributes to declining fecundity with age. Sauer et al. (1991) confirmed that the age of the recipient of donated oocyte or embryos did not appear to influence the pregnancy success rate. However, Sauer and his colleagues also noted that rather than having an inhospitable endometrium, the older women with no ovarian function had an embryo implantation rate that was two to three times that achieved in women whose ovaries were stimulated to produce oocytes: they noted that the stimulated cycles in the recipients of donated oocytes created near-natural endometrial conditions.

Navot et al. (1991) confirmed achievement of high pregnancy rates in a substantially larger sample of 35 women aged 40 and over through oocyte donation. These women had failed at earlier attempts at conception with their own oocytes after both ovulation induction and IVF (they achieved pregnancy rates of $8.3 \%$ and $3.3 \%$ respectively, but no pregnancy was viable). As a result of oocyte donation, the older women achieved a successful pregnancy rate of 30\% (fifteen live births for 50 cycles of donation), which was comparable to the success rate of the younger oocyte donors $(23 \%)$. Navot and his colleagues concluded that the age-related decline in fertility appears to be due to declining oocyte quality, and that with hormonal support the uterus could sustain pregnancy into the late 40 s.

These findings also suggested such agonadal and postmenopausal women might be achieving a higher pregnancy rate than women with ovarian function undergoing IVF, as well as higher rates than under average conditions of normal insemination, because of a better uterine environment.

Later in 1991, Edwards et al. (1991) published a study comparing women who had no evidence of cyclical ovarian activity (acyclic) and women who had normally functioning ovaries (eugonadal) who were undergoing embryo transfers. Edwards and his colleagues use the term embryo transfer to apply to the transfer of both embryos originating from a woman's own oocytes and those originating from a donated oocyte. They make no distinction between 'recipients', except if they are acyclic (and must use donated oocytes), or cyclic or eugonadal (and can therefore use their own oocytes). They used data from an embryo transfer programme in the USA that used fresh embryos, and a programme in the UK that used frozen embryos. Whereas they found that for all the women fecundity declined with age, even in the case of donated oocytes, they confirmed that women who were acyclic and over 40 achieved far higher pregnancy rates with donated oocytes than women of the same age with functioning ovaries who were stimulated ( $25 \%$ versus $10 \%$ and $28 \%$ versus $3 \%$ in the UK and USA, respectively). Similarly, for women in their 30 s who achieved pregnancy rates when cyclic that were comparable to those of acyclic women in their 40s (24-33\%), 
pregnancy rates nearly doubled for acyclic women, who received donated oocytes (37-71\%). These findings confirmed that the high pregnancy rates achieved by agonadal and postmenopausal women are in part due to the pre-existing amenorrhoea that allows for a substitute hormonal regimen that creates a virtually normal and hospitable pre-implantation endometrium. Edwards and his colleagues conclude that acyclic women are more fecund than eugonadal women in embryo transfer programmes primarily because the uterus is dormant prior to hormonal support, and that probably the quality of oocytes from younger donors contributes to the higher pregnancy rates of recipients of donated oocytes. In sum, in older women, as for younger, prematurely menopausal or agonadal women, higher artificial fecundity will result from their fundamental natural infecundity, as long as they can receive oocytes from women who are fundamentally naturally fecund, i.e. from younger women. (Editorial, 1991; Chetkowski et al., 1991; Levran et al., 1991)

Recent data on the question of embryo quality generally support the hypothesis that the reduced quality of oocytes, a problem of ovarian origin, accounts for declining natural fecundity with age. The high incidence of chromosomal abnormalities in first trimester abortions in women of all ages is well known (Chandley, 1982; Boué, Boué \& Gropp, 1985). A rise in spontaneous abortions with chromosomal abnormalities begins in women around the age of 20 and increases exponentially with age. A correlation between age and the frequency of abnormal chromosomal numbers has been demonstrated in unfertilised oocytes from a number of assisted reproductive technology programmes (Planchot et al., 1987, 1988; Bongso et al., 1988; Macas et al., 1990). The mere age of oocytes may be implicated, as there is some evidence of a 'production line' of oocytes, whereby those last to mature, or remaining in older women are the last produced in the fetus (Polani \& Crolla, 1991). Chromosomal anomalies can be explained by errors in oogenesis (the process of successive maturation of the oocytes) and can account for fertilisation failure, overall low pregnancy rates and higher spontaneous abortion rates in older, cyclic women. Recent data on declining luteal phase salivary progesterone levels with age also point to reduced ovarian function to explain loss of fecundity with age (Lipson \& Ellison, 1992).

In sum, recent developments in assisted reproductive technology procedures have provided an investigative tool to develop protocols for oocyte and embryo donation in acyclic, prematurely menopausal and postmenopausal women, that by extrapolation also permit evaluation of the different factors involved in decline of fecundity with age.

\section{Discussion}

\section{Technological and social limits to fertility with age}

Decline in fecundity with age is poorly documented and probably overstated because the sources are data on the menopause, age at last birth in historical and natural fertility populations, and results of artificial insemination, each of which presents particular problems.

Better determination of the age-limits of fecundity in women may have become irrelevant, however, due to recent developments in assisted reproductive technology. The probability of conception in acyclic women is now high, even higher than in young women conceiving naturally, if they are willing to receive donated oocytes. 
The inability to have children can have far-reaching cultural, social, and economic consequences. Through history and across societies, childless couples have resorted to some form of adoption, as well as to deliberate adultery by a woman with a husband's relative (preferably his brother) for tolerable substitutive fatherhood: both are probably practised far more than reported. Raising others' children attests to a predominance of cultural, social, and economic factors over biological factors, and notably over the importance of 'own' genetic offspring for successful parenthood.

Artificial insemination is a very old method of assisted reproduction, practised since the late 18th century. Surrogate motherhood is as old, at least, as the Bible. Modern experience with surrogate motherhood has revealed, however, that the fact of pregnancy and its consequences in the carrying mother substantially reduce its adequacy as an alternative for women. No real option has existed for women on a scale equivalent to the option of artificial insemination for men. Assisted reproductive technology now offers women the same possibility as men to replace their own gametes. Motherhood following pregnancy presents advantages to recipient mothers relative to social fathers of children conceived with donated sperm, and relative to adoption because bonding is facilitated.

Interest in age at motherhood and debate over its limits evolved as post-war generations in developed societies delayed childbearing. The majority have probably succeeded in having children, although perhaps fewer than they wished. Recent increases in age-specific fertility rates of older women in England and Wales, Sweden, Switzerland, and the United States attest to that success (Werner, 1988a,b; OPCS, 1988; Dubois-Arber, Paccaud \& Gutzwiller, 1987; Jones, 1991; Ventura, 1989). A proportion of those who found problems in starting families late achieved pregnancy through medical assistance. Until recently, however, women could not overcome the age-fertility barrier, and poor ovarian function, or cessation of ovarian activity definitively ended prospects for childbearing.

The possibility of age-free gamete reception tests values held regarding maternity. It does not necessarily challenge propriety on the score of gamete donation - artificial insemination is highly acceptable. Nor should it further stretch the tolerance of in-vitro technology, or values regarding the significance and fate of embryos, now long-debated. Nor again should it conflict with received ideas about the age of male or female carers of children: older fathers are generally accepted, as are grandparents raising grandchildren. In addition, research suggests that older mothers may not be subjected to much greater health risks associated with pregnancy than younger mothers, at least within current childbearing limits (Berkowitz et al., 1990). Is it only necessary to change present stereotypes regarding the 'normal' age at motherhood? Can what has been biologically unlikely, but is now technologically possible, cease to be socially unusual (Editorial, 1991; Frydman et al., 1990; Ames et al, 1991)?

There are factors to support a change of attitude towards older mothers. Assisted reproductive technology has developed in parallel with technology to lengthen the lifespan (Barinaga, 1991). Women had a survival advantage over men for a long time, and are now further improving their chances with the apparent cardiovascular protection of hormonal replacement therapy. Certainly at 45,50 and 55 years, women can expect to see their children reach adulthood with some confidence: average life expectancy for women aged 45 ranged from 32 to 39 years in 28 developed countries 
around 1990 (WHO, 1993). Even at 65 years, women's expectation of life already exceeded 18 years, the age of legal adulthood of children, in eighteen of those countries, and surpassed 20 years in four (France, Iceland, Switzerland and Japan).

Women who demand late motherhood are the most likely source of pressure for its social acceptability. As the option becomes better known, it will be attractive to increasing numbers of older women who might otherwise have missed the opportunity for motherhood, or never had it. Young women will also have the option to freeze embryos from their own oocytes to preserve their chance of motherhood later (Sèle et al., 1989). Limited availability and cost imply that the new technology will not have a demographic impact, at least in the foreseeable future. In any case, the vast majority of women will have their own children. Nor are all women who could benefit likely to choose late-age childbearing.

Nevertheless, the existence of the technology is bound to modify thoughts and attitudes to motherhood. As an option to adoption, oocyte or embryo donation may contribute more to blur the line between genetic and social parenthood. The notion of parenthood may one day be irrevocably altered, and the nature/nurture issue lose its edge because of the possibility, as much as the practice, of pregnancy with another woman's gamete.

\section{References}

Ames, K., Denworth, L., Wright, L., Quade, V., Iarovici, D. \& Hager, M. (1991) And donor makes three. Newsweek, September 30.

Barrett, J. C. \& Marshall, J. (1969) The risk of conception on different days of the menstrual cycle. Popul. Stud. 23, 455.

Barinaga, M. (1991) How long is the human life-span? Science, 254, 936.

Berkowitz, G. S., Skovron, M. L., Lapinski, R. H. \& Berkowitz, R. L. (1990) Delayed childbearing and the outcome of pregnancy. New Engl. J. Med. 322, 659.

Blanc, A. K. \& RutenberG, N. (1991) Coitus and contraception: the utility of data on sexual intercourse for family planning programs. Stud. Fam. Plan. 22, 162.

Bongaarts, J. (1982) Infertility after age 30: a false alarm. Fam. Plann. Perspect. 14, 75.

Bongaarts, J. \& Potter, R. G. (1983) Fertility, Biology and Behavior: An Analysis of the Proximate Determinants. Academic Press, New York.

Bongso, A., Chye, N. S., Ratman, S., Sathananthan, H. \& Wong, P. C. (1988) Chromosome anomalies in human oocytes failing to fertilize after insemination in vitro. Hum. Reprod. 3, 645.

BouÉ, A., BouÉ, J. \& Gropp, A. (1985) Cytogenetics of pregnancy wastage. In: Advances in Human Genetics. Edited by H. Harris \& K. Hirschhorn. Plenum, New York.

Chandeey, A. C. (1982) Normal and abnormal meiosis in man and other mammals. In: Genetic Control of Gamete Production and Function. Edited by P. G. Crosignani \& B. L. Rubin. Academic Press, London.

Chetkowski, R. J., Rode, R. A., Burruel, V. \& Nass, T. E. (1991) The effect of pituitary suppression and the women's age on embryo viability and uterine receptivity. Fert. Steril. 56, 1095.

Dubois-Arber, F., Paccaud, F. \& Gutzwiller, F. (1987) Epidémiologie de la Stérilité: Démographie de la Fécondité en Suisse (Revue des enquêtes de prévalence publiées). Cahiers de Recherches et de Documentation 17. Institute Universitaire de Médecine Sociale et Préventive, Lausanne. 
EdTORIal (1991) Declining fertility: egg or uterus? Lancet, 338, 285.

Edwards, R.G., Morcos, S., Macnamee, M., Balmaceda, J. P., Walters, D. E. \& Asch, R. (1991) High fecundity of amenorrhoeic women in embryo-transfer programmes. Lancet, 338, 292.

Frydman, R., Letur-Könirsch, H., De Ziegler, D., Bydlowski, M., Raoul-Duval, A. \& Selva, J. (1990) A protocol for satisfying the ethical issues raised by oocyte donation: the free, anonymous, and fertile donors. Fert. Steril. 53, 666.

GosDen, R. G. (1985) Maternal age: a major factor affecting the prospects and outcome of pregnancy. Ann. New York Acad. Sci. 442, 45.

Gray, R. H. (1979) Biological factors influencing the reproductive lifespan. In: Natural Fertility: Patterns and Determinants of Natural Fertility. Edited by H. Leridon \& J. Menken. Ordina, Liège.

HeNRY, L. (1965) French statistical research in natural fertility. In: Public Health and Population Change. Edited by M. C. Sheps \& J. C. Ridley. University of Pittsburgh Press, Pittsburgh.

HoRnSBY, P. B. \& WILCOX, A. J. (1989) Validity of questionnaire information on frequency of coitus. Am. J. Epidemiol. 130, 94.

InstrTUte for Resource DeveloPment (1987a) Model 'A' Questionnaire With Commentary for High Contraceptive Prevalence Countries. Basic Documentation number 1. Institute for Resource Development, Columbia.

Institute for Resource Development (1987b) Model ' $B$ ' Questionnaire With Commentary for Low Contraceptive Prevalence Countries. Basic Documentation number 2. Institute for Resource Development, Columbia.

JACOBSON, A. \& GALEN, D. I. (1990) A successful term pregnancy in a 49-year-old woman using donated oocytes. Fert. Steril. 54, 546.

JAMEs, W. H. (1983) Decline in coital rates with spouses' ages and duration of marriage. $J$. biosoc. Sci. 15, 83.

JoNEs, C. (1991) Birth statistics 1990. Popul. Trends, 65, 9.

Kerin, J. F., Warnes, G. M., Quinn, P., Kirby, C., Jeffrey, R., Matthews, C., Seamark, R. S., Texler, K., Antonas, B. \& Cox, W. L. (1984) In-vitro fertilization and embryo transfer program. J. In Vitro Fert. Embr. Trans. 1, 63.

Lenton, E. A., Weston, G. A. \& Cooke, I. D. (1977) Long-term follow-up of the apparently normal couple with a complaint of infertility. Fert. Steril. 28, 913.

Levran, D., Ben-Shlomo, I., Dor, J., Ben-Rafael, Z., Nebel, L. \& Mashiach, S. (1991) Aging of endometrium and oocytes: observations on conception and abortion rates in egg donation model. Fert. Steril. 56, 1091.

Lipson, S. F. \& Ellison, P. T. (1992) Normative study of age variation in salivary progesterone profiles. J. biosoc. Sci. 24, 233.

Lutjen, P., Trounson, A., Leeton, J., Findlay, J., Wood, C. \& Renou, P. (1984) The establishment and maintenance of pregnancy using in vitro fertilization and embryo donation in a patient with primary ovarian failure. Nature, 307, 174.

Macas, E., Floershein, Y., Holtz, E., Imthurn, B., Keller, P. J. \& Walt, H. (1990) Abnormal chromosomal arrangements in human oocytes. Hum. Reprod. 5, 703.

Medical Research International, Society for Assisted Reproductive Technology \& The American Fertility Society (1992) In vitro fertilization-embryo transfer (IVF-ET) in the United States: 1990 results from the IVF-ET Registry. Fert. Steril. 57, 15.

Menken, J., Trussell, J. \& Larsen, U. (1986) Age and infertility. Science, 233, 1389.

Navot, D., Bergh, P. A., Williams, M. A., Garrisi, G. J., Guzman, I., Sandler, B. \& GruNFELD, L. (1991) Poor oocyte quality rather than implantation failure as a cause of age-related decline in female fertility. Lancet, 337, 1375.

OPCS (1988) Live births in 1987. Popul. Trends, 53, 35. 
Padilla, S. L. \& Garcia, J. E. (1989) Effect of maternal age and number of in-vitro fertilization procedures on pregnancy outcome. Fert. Steril. 52, 270.

Piette, C., de Mouzon, J., Bachelot, A. \& Spira, A. [FIVNAT] (1990) In-vitro fertilization: influence of women's age on pregnancy rates. Hum. Reprod. 5, 56.

Planchot, M., Junca, A.-M., Mandelbaum, J., de Grouchy, J., Salat-Baroux, J. \& Cohen, J. (1987) Chromosome investigations in early life. II. Human preimplantation embryos. Hum. Reprod. 2, 29.

Planchot, M., Veiga, A., Montagut, J., de Grouchy, J., Calderon, G., Lepretre, S., Junca, A.-M., Santalo, J., Carles, E., Mandelbaum, J., Barri, P., Degoy, J., Cohen, J., Egozcue, J., Sabatier, J. C. \& Salat-Baroux, J. (1988) Are clinical and biological IVF parameters correlated with chromosomal disorders in early life? A multicentric study. Hum. Reprod. 3, 627.

Polani, P. E. \& Crolla, U. (1991) A test of the production line hypothesis of human oogenesis. Hum. Genet. 86, 125.

SAIDDUdDin, S. \& Zussenhaus, J. P. (1979) Estrous cycles, decidual cell response and uterine estrogen and progesterone receptor in Fischer 344 virgin aging rats (40503). Proc. Soc. exp. Biol. Med. 161, 119.

Sauer, M. V., Paulson, R. J. \& Lobo, R. A. (1989) Simultaneous establishment of pregnancies in two ovarian failure patients using one oocyte donor. Fert. Steril. 52, 1072.

Sauer, M. V., Paulson, R. J. \& Lobo, R. A. (1990) A preliminary report on oocyte donation extending reproductive potential to women over 40. New Engl. J. Med. 323, 17, 1157.

Sauer, M. V., Paulson, R. J., Macaso, T. M., Francis, M. M. \& Lobo, R. A. (1991) Oocyte and pre-embryo donation to women with ovarian failure: an extended clinical trial. Fert. Steril. 55, 39.

Schwartz, D. \& Mayaux, M. J. (1982) Female fecundity as a function of age: results of artificial insemination in 2193 multiparous women with azoospermic husbands. New Engl. $J$. Med. 305, 404.

SEgal, S. \& CASPER, R. F. (1990) The response to ovarian hyperstimulation and in-vitro fertilization in women older than 35 years. Hum. Reprod. 5, 255.

Sèle, B., Racinet, C., Quenard, N. \& Bergues, U. (1989) Pregnancy after oocyte collection and total ovariectomy. New Engl. J. Med. 1756.

van Noord-Zaadstra, B. M., Looman, C. W. N., Alsbach, H., Dik, J., Habbema, F., te Velde, E. R. \& KARBAAT, J. (1991) Delaying childbearing: effect of age on fecundity and outcome of pregnancy. Br. med. J. 302, 1361.

Ventura, S. J. (1989) Trends and Variations in First Births to Older Women, 1970-1986. Vital and Health Statistics, Series 21, No 47. UN, New York.

Vincent, P. (1950) La stérilité physiologique des populations. Population, 5, 45.

Werner, B. (1988a) Fertility trends in the UK and thirteen other developed countries, 1966-1986. Popul. Trends, 51, 18.

Werner, B. (1988b) Fertility data from the Population (Statistics) Act in England and Wales: 1938-1988. Popul. Trends, 52, 15.

Westoff, C. F. (1974) Coital frequency and contraception. Fam. Plann. Perspect. 6, 136. WHO (1993) World Health Statistics Annual 1992. World Health Organization, Geneva.

WHO ScIENTIFIC Group (1981) Research on the Menopause. Technical Report Series 670. World Health Organization, Geneva. 